\title{
LEVANTAMENTO DE MANIFESTAÇÕES PATOLÓGICAS EM EDIFICAÇÕES POPULARES NA CIDADE DE CASCAVEL-PR
}

\author{
PAGANIN, RICARDO \\ Engenheiro Civil \\ Centro Universitário Assis Gurgacz \\ Paraná; Brasil \\ engpaganin@gmail.com
}

\author{
CHIAMENTI, LUIS HENRIQUE \\ Engenheiro Civil \\ Centro Universitário Assis Gurgacz \\ Paraná; Brasil \\ henriquecht@hotmail.com
}

\author{
PIVATTO, ELISSON ANTONIO \\ Engenheiro Civil \\ Centro Universitário Assis Gurgacz \\ Paraná; Brasil \\ eng.elissonpivatto@gmail.com
}

\author{
RACHID, LIGIA ELEODORA FRANCOVIG \\ Engenheira Civil \\ Centro Universitário Assis Gurgacz \\ Paraná; Brasil \\ ligia@fag.edu.br
}

\begin{abstract}
RESUMO
Devido à busca incessante pelo lucro e pela competitividade, o critério qualidade muitas vezes é esquecido pelos construtores, gerando um produto final com várias inconformidades, vícios construtivos e manifestações patológicas, afetando a eficiência e a durabilidade das construções, bem como a segurança dos usuários. Esta pesquisa levantou as manifestações patológicas em edificações populares localizadas na cidade de Cascavel - PR, procurando indicar a frequência dos problemas identificados e verificar a influência das ampliações nos imóveis em relação ao surgimento das manifestações patológicas. Para a realização dessa pesquisa, foi utilizada uma abordagem quantitativa e qualitativa das manifestações patológicas presentes em 11 residências populares, construídas na década de 90 pelo programa de habitação popular da Companhia de Habitação do Paraná - COHAPAR. O levantamento dos problemas foi realizado com visitas in loco e com a utilização de anotações de registros fotográficos para, embasando-se na bibliografia, sugerir as prováveis causas e um método de reparo que pudesse ser aplicado, além da aplicação da metodologia GUT (Gravidade, Urgência e Tendência) para análise. Observou-se que, nas edificações vistoriadas, as manifestações patológicas com maior frequência foram as fissuras verticais e horizontais, com $38 \%$ do total das manifestações. Manifestações relacionadas diretamente com a umidade e infiltrações também apresentaram uma incidência alta na maior parte dos imóveis. Os locais mais afetados por manifestações patológicas nas edificações foram às áreas externas, por serem mais suscetíveis às intempéries do ambiente.
\end{abstract}

Palavras-chave: ampliações, fissuras, GUT, patologia, edificações populares.

\section{ABSTRACT}

Due to the relentless pursuit of profit and competitiveness, builders, generating a final product with various nonconformities, constructive defects and pathological manifestations, affecting the efficiency and durability of buildings, as well as the safety of users, often overlook the quality criterion. This research raised the pathological manifestations in popular buildings located in the city of Cascavel - PR, seeking to indicate the frequency of the identified problems and to verify the influence of the expansions in the real estate in relation to the emergence of pathological manifestations. To carry out this research, a quantitative and qualitative approach was used to the pathological manifestations present in 11 popular residences, built in the 90 s by the popular housing program of the Paraná Housing Company - COHAPAR. The survey of the problems was carried out with on-site visits and the use of photographic record annotations to, based on the bibliography, suggest the probable causes and a repair method that could be applied, in addition to the application of the GUT methodology. Urgency and Trend) for analysis. In the surveyed buildings, the most frequent pathological manifestations were vertical and horizontal fissures, with $38 \%$ of the total manifestations. Manifestations directly related to humidity and infiltration also had a high incidence in most buildings. The places most affected by pathological manifestations in buildings were the external areas, because they are more susceptible to the weather.

Keywords: enlargements, cracks, GUT, pathology, popular buildings. 


\section{INTRODUÇÃO}

Segundo Vieira (2016), uma edificação é o resultado da combinação de diversos materiais heterogêneos, construídos com mão de obra, muitas vezes, pouco qualificada e que, com a combinação de fatores ambientais e a falta de conservação acabam acelerando o aparecimento de fenômenos patológicos, prejudicando a funcionalidade e a segurança destas edificações.

Para Gomes (2016), um dos principais fatores para o surgimento destas manifestações patológicas é a má conduta construtiva adotada em boa parte das obras, como o não atendimento das normas técnicas vigentes, muitas vezes provenientes de projetos ineficientes, a falta de fiscalização pelo responsável técnico dos métodos construtivos adequados, ou ainda a inexistência de um profissional habilitado, quando da necessidade de alguma intervenção posterior, como reformas e ampliações.

Para Lichtenstein (1986), parte dos edifícios construídos não apresenta um desempenho satisfatório, porém a preocupação com seus problemas e as causas desses problemas é antiga e nasceu juntamente com o ato de construir. Com a aplicação do conceito de desempenho na engenharia civil, as construções começaram a ser analisadas de forma global e os problemas relativos à falta de desempenho deixaram de ser tratados como simples defeitos.

Helene (2003), afirma que as manifestações patológicas nas edificações não ocorrem de forma isolada ou sem motivo. Elas têm sua origem relacionada à ocorrência de algum erro durante alguma etapa do processo construtivo, sendo de suma importância conhecer a origem do problema e o histórico da construção, para então apontar em qual etapa ocorreu o erro que gerou o problema patológico.

Para Alves, Thomé e Tosta (2017), o crescimento desordenado das cidades e o grande aumento populacional nas últimas décadas acarretaram em um déficit habitacional no país. A iniciativa público-privada investiu na implantação de empreendimentos e habitações populares, como o programa Minha Casa Minha Vida. Porém, devido à precária fiscalização, as manifestações patológicas têm sido precocemente detectadas nestas habitações.

Dessa forma, realizou-se o levantamento das manifestações patológicas presentes em habitações populares que sofreram ampliações, na cidade de Cascavel-PR. Além disso, pretendeu-se também indicar a frequência das manifestações encontradas e a influência das ampliações no seu surgimento.

\section{METODOLOGIA}

A pesquisa foi realizada com a utilização do método qualitativo de análise, e foram levantadas as manifestações patológicas presentes nas edificações, através de inspeções visuais e, posteriormente, quantificadas e identificadas por meio de revisão bibliográfica.

De acordo com Richardson et al. (1989), o método quantitativo caracteriza-se pelo emprego da quantificação, nas modalidades de coleta de informações e tratamento através de técnicas. Por outro lado, o método qualitativo não emprega instrumentos estatísticos para a análise dos problemas, e não tem como princípio medir ou enumerar categorias. Para Rosental e Frémontier-Murphy (2001), de forma geral, a pesquisa quantitativa é passível de ser medida em escala numérica e a qualitativa não.

Com a quantificação das manifestações patológicas mais recorrentes foi efetuado uma análise da influência das ampliações nos problemas apresentados. A análise foi auxiliada pela aplicação de uma matriz GUT - gravidade, urgência e tendência, a qual serviu de base para a classificação dos principais problemas verificados nos imóveis.

\subsection{Caracterização da amostra}

Foram analisadas 11 edificações dentre as 232 casas similares encontradas no bairro Brasília, da cidade de Cascavel PR, de forma não uniforme, que foram construídas pela Companhia de Habitação do Paraná - COHAPAR. O número reduzido da análise em relação ao total da amostra se deu devido à necessidade de autorização e disponibilidade dos moradores em horário comercial, tornando difícil o acesso aos imóveis. 
Os imóveis em estudo estão habitados e todos tiveram alguma intervenção de ampliação ao longo dos anos sendo que foram construídos há aproximadamente 18 anos pela COHAPAR, juntamente com a iniciativa privada. Das onze residências analisadas, seis tiveram um alto grau de ampliação ou intervenção.

Antes das ampliações, a estrutura básica das casas (Figura 1) continha sala, dois quartos, cozinha, banheiro social e lavanderia. Havia mais de um modelo de disposição dos cômodos, porém a área das edificações eram as mesmas. A cobertura possuía duas águas, sem calçada de proteção no entorno do imóvel e sem garagem.
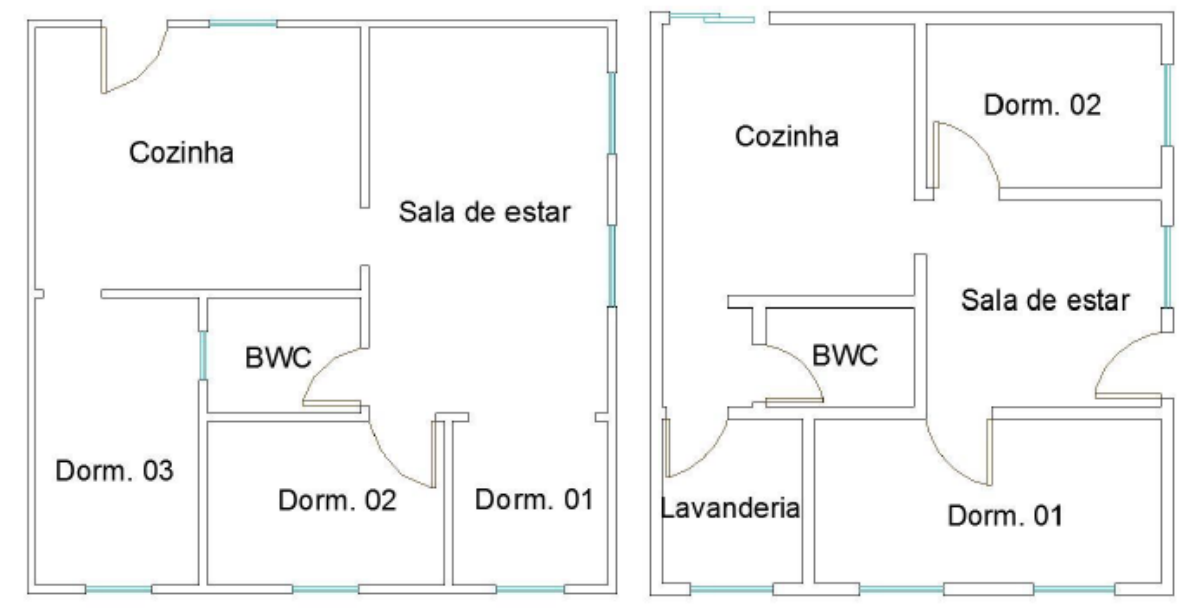

Figura 1: Estrutura básica das edificações analisadas.

Devido à necessidade, com o decorrer dos anos, os proprietários realizaram intervenções, a fim de ampliar seus imóveis, seja pelo crescimento de suas famílias, por ascensão econômica ou pela busca de maior conforto para seus ocupantes. Na Figura 2 pode-se observar uma relação das casas analisadas, seu endereço, a idade dos imóveis e a área total construída.

\begin{tabular}{|c|c|c|c|}
\hline Casa & Endereço & Idade (Anos) & Área Const. $\left(\mathbf{m}^{\mathbf{2}}\right.$ ) \\
\hline 1 & Rua Estefânia Luisa Vilaça, 67 & 18 & 86,10 \\
\hline 2 & Rua Antônio Carlos Kraide, 590 & 18 & 78,00 \\
\hline 3 & Rua Ipanema, 1767 & 19 & 101,85 \\
\hline 4 & Rua Noel Rosa, 552 & 18 & 101,34 \\
\hline 5 & Rua Ciro Monteiro, 688 & 18 & 67,50 \\
\hline 6 & Rua Heitor Villa Lobos, 868 & 18 & 143,00 \\
\hline 7 & Rua Noel Rosa, 638 & 19 & 43,80 \\
\hline 8 & Rua Noel Rosa, 542 & 18 & 85,80 \\
\hline 9 & Rua Noel Rosa, 518 & 18 & 96,50 \\
\hline 10 & Rua Antônio Carlos Kraide, 600 & 18 & 141,59 \\
\hline 11 & Rua Antônio Carlos Kraide, 570 & 18 & 78,00 \\
\hline
\end{tabular}

Figura 2: Relação dos imóveis objeto da pesquisa.

\subsection{Instrumentos e procedimentos para coleta de dados}

A coleta de dados foi realizada pelos autores por inspeção visual das manifestações patológicas nas residências, com o agendamento de visitas, programadas para os meses de dezembro de 2018 e janeiro e fevereiro de 2019, gerando registros fotográficos das manifestações patológicas encontradas.

As vistorias ocorreram conforme disponibilidade dos moradores e agendamento prévio, tanto em dias com alta luminosidade ambiente, como em dias chuvosos, ou com baixa luminosidade. Para auxiliar no levantamento dos problemas das edificações, foi utilizada uma adaptação do formulário para o levantamento de manifestações patológicas, proposto por Paganin (2014). Tal formulário possui a identificação do problema patológico e relaciona a anamnese do problema.

A classificação das manifestações patológicas de acordo com a gravidade foi dividida em crítico, regular e mínimo, de acordo com a definição da Norma de Inspeção Predial do Instituto Brasileiro de Avaliações e Pericias de Engenharia (IBAPE, 2012). 


\subsection{Análise dos dados}

Com todas as vistorias finalizadas e o devido registro fotográfico de cada imóvel, foi feita a análise dos problemas com base em revisões bibliográficas, para detectar as manifestações patológicas, suas prováveis causas, origens e possíveis riscos inerentes.

A quantificação das manifestações foi tabulada em planilha e apresentada em gráficos, para definir a mais recorrente e servir de base para a matriz GUT. Para Sotille (2014), a matriz de priorização GUT é uma ferramenta importante utilizada na solução de problemas para definir prioridades quanto às manifestações encontradas. A matriz GUT consiste em uma ferramenta que auxilia na resolução dos problemas, classificando-os de acordo com sua Gravidade, Urgência e Tendência (GUT). A gravidade trata do impacto que o problema irá gerar, a urgência define o prazo ou tempo disponível para que o problema seja solucionado, e a tendência relaciona a probabilidade que o problema possui de crescer com o passar do tempo.

Cada fator é correlacionado a uma pontuação que varia de 1 a 5 , sendo 5 a maior pontuação. Definidos os pontos para cada problema, é realizada a multiplicação dos mesmos, gerando uma pontuação máxima de 125 pontos. Define-se qual o problema requer uma atenção imediata baseado na maior pontuação atingida. Um modelo da tabela utilizada para o tratamento dos dados pode ser observada na Figura 3.

\begin{tabular}{|c|c|c|c|c|c|c|c|}
\hline \multicolumn{8}{|c|}{ Modelo GUT } \\
\hline \multicolumn{8}{|c|}{$\begin{array}{l}\text { Preenchimento: Inserir as manifestações patológicas na primeira coluna em verde e assinalar a } \\
\text { pontuação correspondente às colunas } \mathrm{G}, \mathrm{U} \text { e T, de acordo com, a classificação abaixo. A última } \\
\text { coluna, que indica a prioridade, é computada automaticamente. Ao final, será organizada a } \\
\text { manifestação patológica da maior pontuação para a menor, facilitando a visualização das } \\
\text { demandas consideradas de maior prioridade. }\end{array}$} \\
\hline Casa $\mathrm{n}^{\circ}:$ & \multicolumn{2}{|c|}{ Problemas } & Gravidade & & rgência & Tendência & Prioridade \\
\hline$x x$ & \multicolumn{2}{|c|}{ Manifestação patológica } & & & & & \\
\hline \multicolumn{2}{|c|}{$\overline{\text { GRAVIDADE }}$} & \multicolumn{3}{|c|}{ URGÊNCIA } & \multicolumn{3}{|c|}{ TENDÊNCIA } \\
\hline \multicolumn{2}{|c|}{1 = SEM GRAVIDADE } & \multicolumn{3}{|c|}{1 = NÃO TEM PRESSA } & \multicolumn{3}{|c|}{1 = NÃ̃ VAI PIORAR } \\
\hline \multicolumn{2}{|c|}{2 = POUCO GRAVE } & \multicolumn{3}{|c|}{2 = PODE ESPERAR UM POUCO } & \multicolumn{3}{|c|}{$\begin{array}{l}2=\text { VAI PIORAR EM LONGO } \\
\text { PRAZO }\end{array}$} \\
\hline \multicolumn{2}{|l|}{$3=$ GRAVE } & \multicolumn{3}{|c|}{3 = O MAIS CEDO POSSÍVEL } & \multicolumn{3}{|c|}{$\begin{array}{l}3=\text { VAI PIORAR EM MÉDIO } \\
\text { PRAZO }\end{array}$} \\
\hline \multicolumn{2}{|c|}{4 = MUITO GRAVE } & \multicolumn{2}{|c|}{$4=$ COM ALGUMA URGÊNCIA } & \multicolumn{4}{|c|}{$\begin{array}{l}4=\text { VAI PIORAR EM POUCO } \\
\text { TEMPO }\end{array}$} \\
\hline \multicolumn{2}{|c|}{$5=$ EXTREMAMENTE GRAVE } & \multicolumn{2}{|c|}{$5=$ AÇÃO IMEDIATA } & \multicolumn{4}{|c|}{5 = VAI PIORAR RAPIDAMENTE } \\
\hline
\end{tabular}

Figura 3: Exemplo da classificação de prioridade aplicada à metodologia GUT.

Além disso, foram apresentados gráficos relacionando a frequência das manifestações patológicas nos cômodos dos imóveis para uma melhor observação dos cômodos mais e menos afetados.

\section{ANÁLISES E DISCUSSÕES}

\subsection{Manifestações patológicas identificadas na edificação}

Durante a realização dos trabalhos de pesquisa foram identificadas diversas manifestações patológicas nas edificações, sendo as mais comuns as fissuras e os problemas relacionados à pintura. Uma das manifestações patológicas mais frequentes nas edificações foi a presença de fissuras horizontais. As fissuras horizontais podem manifestar-se por diferentes motivos, embora pode-se observar que nas edificações vistoriadas a causa em sua maioria foi semelhante.

O cômodo que mais apresentou incidência desta manifestação nas residências foi a área externa, possivelmente devido sua área ser maior. No entanto, foi possível verificar esta manifestação patológica em todos os ambientes, como pode ser observar no gráfico da Figura 4, onde se observa um gráfico da frequência do problema em relação aos cômodos das edificações visitadas. 


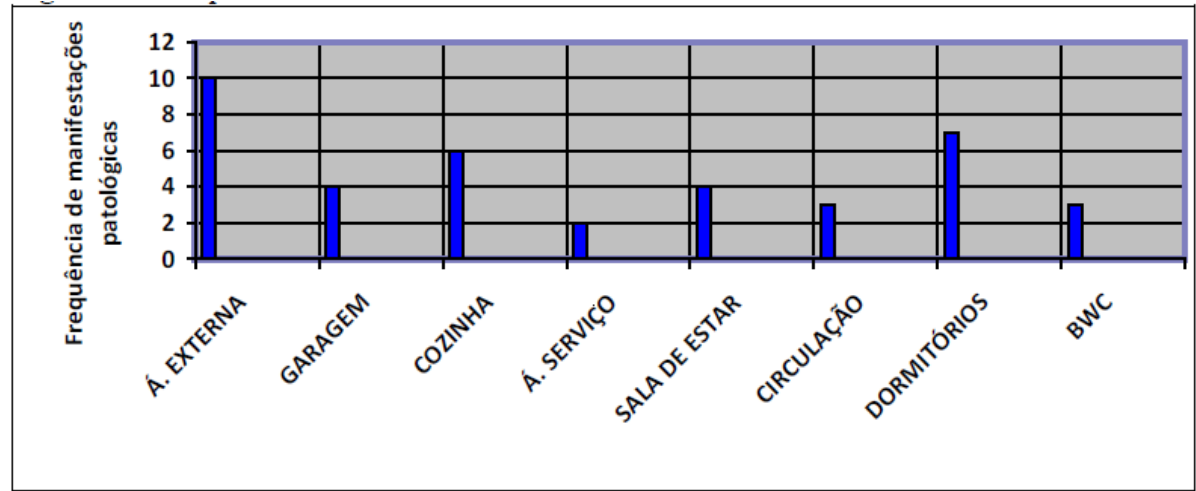

Figura 4: Frequência de fissuras horizontais em relação aos cômodos das edificações.

Foi possível identificar que a conservação dos imóveis não teve influência na incidência de fissuras horizontais, uma vez que residências com conservação regular apresentaram incidências semelhantes aquelas com conservação ruim. Além disso, foi possível observar que os cômodos ampliados obtiveram uma tendência maior ao surgimento desta manifestação patológica. Um exemplo deste problema pode ser observado na Figura 5.

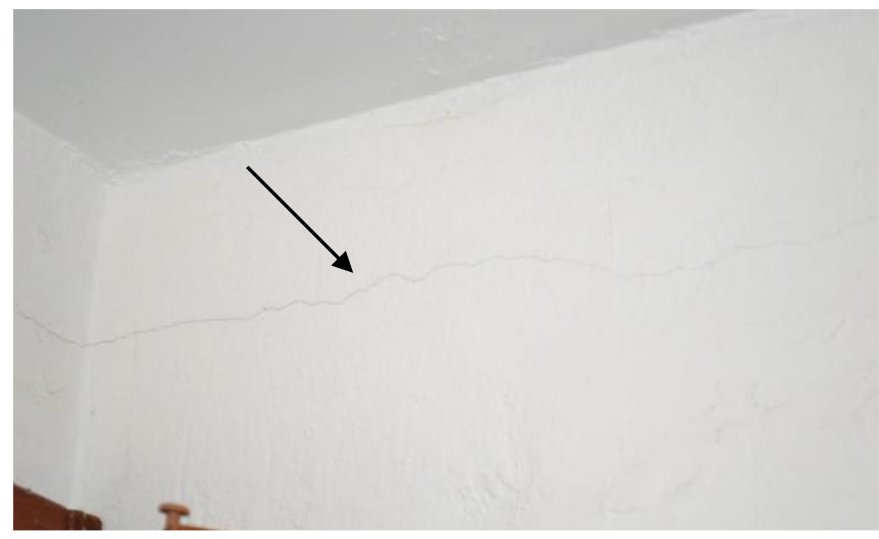

Figura 5: Exemplo de fissura horizontal na parte superior da parede do dormitório da edificação número 3.

Os dormitórios foram os ambientes com a segunda maior incidência de fissuras horizontais, uma vez que ao realizar as ampliações os moradores optavam por retirar paredes e aumentar a área dos dormitórios existentes, ou ainda, acrescentar novos dormitórios. Desta maneira, possivelmente, ao retirar uma das paredes houve uma sobrecarga nas demais paredes, ocasionando estas fissuras.

Segundo Sahlin (1971, apud Magalhães, 2004), fissuras horizontais podem surgir devido à sobrecarga, pelo carregamento excessivo de compressão, ou possíveis solicitações de flexocompressão, gerando a ruptura dos componentes na argamassa de assentamento, tijolos ou blocos de furos horizontais.

Zanzarini (2016) ainda afirma que fissuras horizontais no topo das paredes também podem surgir pelo abaulamento das lajes, acrescido ainda de tensões de tração e de cisalhamento nas paredes, como observado no esquema da Figura 5.

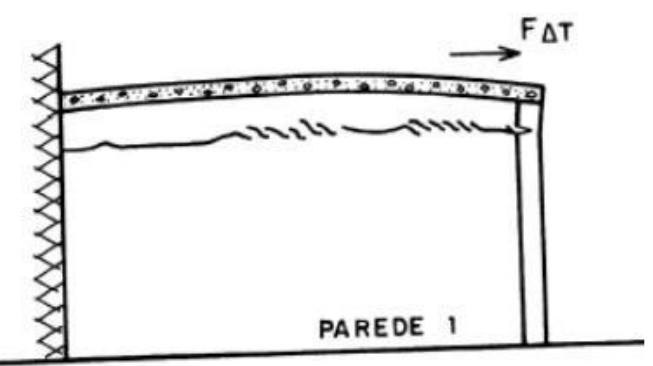

Figura 5: Esquema representando fissuração horizontal na parte superior da parede de alvenaria.

Fonte: THOMAZ (1989). 
Segundo Silva e Sobrinho (2016), para reparar fissuras horizontais é necessário investigar o que pode estar gerando o problema, para cessar a sobrecarga existente e prosseguir com a reparação da fissura. Para a reparação visual é recomendável que seja feita a remoção do revestimento, realizada a limpeza da área, para então aplicar uma argamassa polimérica com tela poliéster, transpassada em aproximadamente $20 \mathrm{~cm}$ para cada lado da fissura. Finalizado este procedimento, pode-se recompor a área com argamassa polimérica e realizar o acabamento, respeitando um prazo de no mínimo 21 dias para a aplicação do emassamento e pintura.

Nas edificações também foram identificadas fissuras diagonais em edificações com maior grau de ampliação, a frequência desse tipo de manifestação patológica em relação aos cômodos da edificação pode ser observada no gráfico da Figura 6.

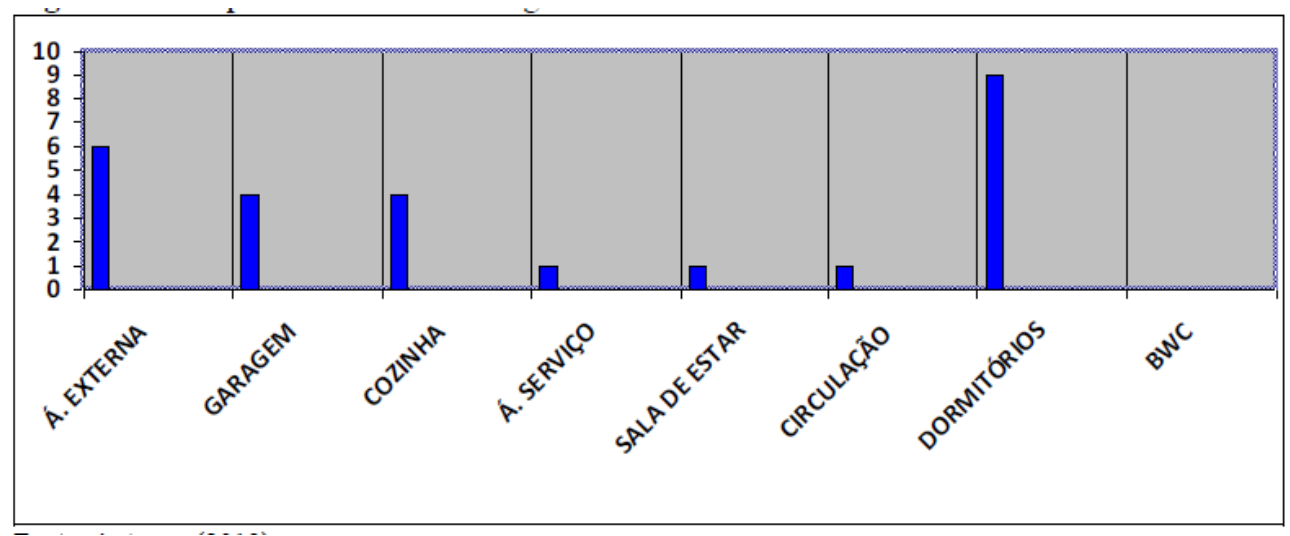

Figura 6: Frequência de fissuras diagonais em relação aos cômodas das edificações.

De acordo com o gráfico da Figura 6, os dormitórios foram os cômodos mais afetados nas residências analisadas. Este fato pode ser explicado devido ao maior número deste tipo de cômodo nas residências, o que acaba gerando uma frequência maior devido a presença de aberturas.

Além disso, a ausência de vergas e contravergas nas aberturas pode ser o principal fator responsável pelo surgimento dessa manifestação patológica, uma vez que durante a vistoria os moradores informaram que, durante as ampliações, foi possível detectar a ausência destes elementos. Na Figura 7 é possível observar uma fissura diagonal causada pela ausência de contraverga na janela de um dormitório.

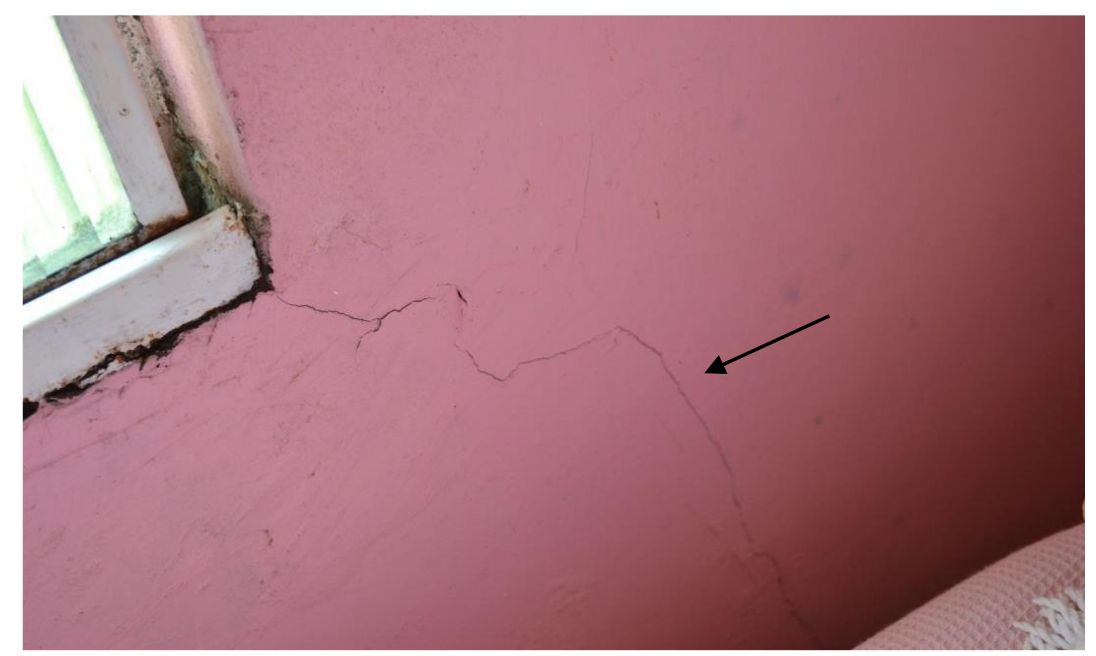

Figura 7: Fissura diagonal no vértice da janela do dormitório.

De acordo com Ripplinger (2011), o aparecimento de fissuras diagonais é normalmente notado ao lado das aberturas, onde se encontra o ponto de tensões, podendo ocorrer também devido a uma distribuição inadequada de esforços, referente ao ponto de transmissão das cargas verticais. 
Segundo Sampaio (2010, apud Refati, 2013) a falta de verga e contraverga, ou o dimensionamento exagerado da mesma, faz com que apareçam fissuras nas paredes, sendo essas mais frequentes próximas às aberturas e em forma diagonal, partido dos vertices, como pode ser exemplificado no esquema da Figura 8.

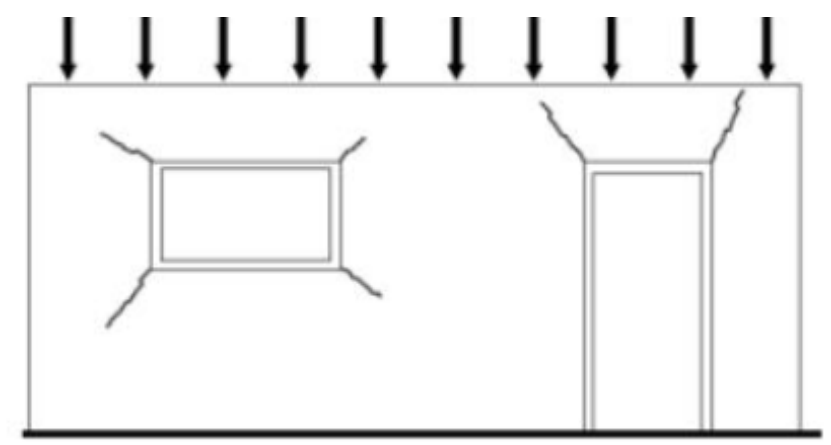

Figura 8: Fissura diagonal no vértice da janela do dormitório.

Fonte: BAUER (2007).

Para Lordsleem (1997, apud Muci, Netto e Silva, 2014) o reparo paliativo da fissura diagonal pode ser realizado com a execução de um corte com $20 \mathrm{~mm}$ de largura e $10 \mathrm{~mm}$ de profundidade em forma de "V" ou retangular no local onde se encontra a fissura. Emprega-se então um selante flexível para preencher o corte executado, a fim de permitir que a fissura movimente-se livremente.

No entando Lordsleem (1997, apud Muci, Netto e Silva, 2014) destacam que em fissuras diagonais causadas pela ausência de verga e contraverga o ideal é a retirada da esquadria afetada e a correta execução destes elementos para que a manifestação patológica não volte a ocorrer.

Nas edificações também foram identificados pontos de destacamento da pintura, tal problema foi frequente uniformemente em todas as edificações vistoriadas. A distribuição desse tipo de manifestação patológica nos cômodos das edificações pode ser observada no gráfico da Figura 9.

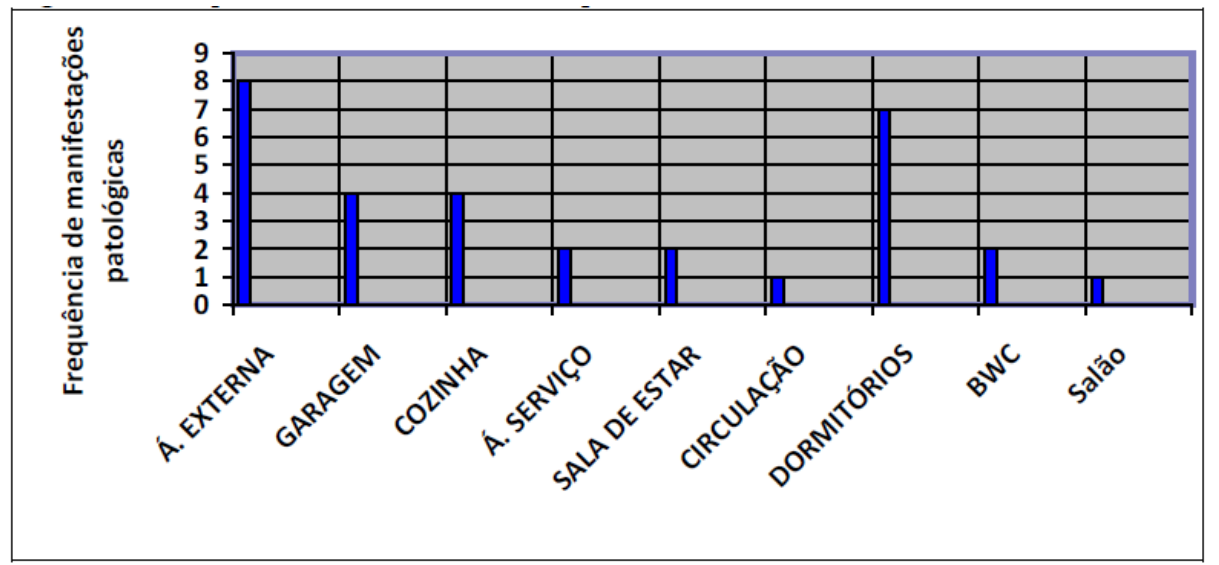

Figura 9: Frequência de destacamento da pintura em relação aos cômodas das edificações.

De acordo com o gráfico da Figura 9 é possível observar que os cômodos mais afetados por esta manifestação foram a área externa e os dormitórios. Por também estar relacionada com a umidade, a maior frequência desta manifestação nestes cômodos pode ter a mesma origem das já citadas nos itens anteriores, que são a alta presença de umidade nos cômodos e a baixa incidência de sol.

Segundo Netto e Teixeira (2015) o destacamento da pintura ocorre devido à falta de aderência entre a tinta e a parede, ocasionando o desprendimento de pedaços de tinta, como se fossem cascas. As principais causas desta manifestação patológica estão relacionadas com superfícies sujas ou contaminadas durante a aplicação, ou ainda devido à interação da umidade com altas temperaturas da superfície, durante sua aplicação ou posterior. Um exemplo desse tipo de manifestações patológica encontrado nas edificações pode ser observado na Figura 10. 


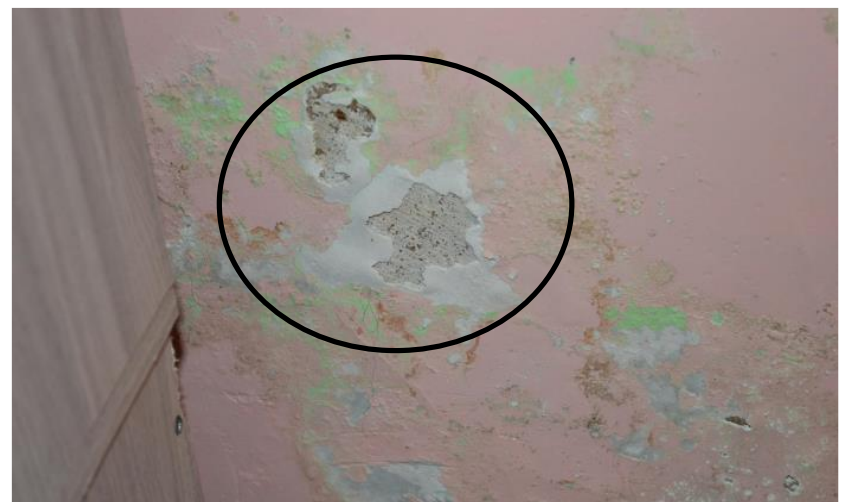

Figura 10: Empolamento e destacamento da pintura observado na edificações.

Giordani (2016) afirma que o destacamento da pintura ocorre pela quantidade excessiva de pó e sujeira na superfície da parede, antes de sua aplicação. Esta manifestação patológica pode estar relacionada com a superfície do reboco mal preparada, com uma repintura sobre uma camada muito antiga de tinta ou também a aplicação de uma tinta muito diluída.

Segundo Freire (2017) os fatores que estão diretamente ligados à manifestações patológicas em tintas vão desde a escolha do produto e a preparação da superfície até as condições climáticas. Para corrigir problemas de destacamento de pintura é necessária uma renovação completa da pintura, com remoção total da pintura antiga, lixamento, limpeza da superfície e aplicação da nova tinta. Além disso, é importante atentar para a homogeneização e diluição correta da tinta antes da aplicação.

\subsection{Frequências e origens dos problemas patológicos}

No gráfico da Figura 11 pode ser observada a incidência total d as manifestações patológicas identificadas, relacionando a porcentagem total dos problemas em relação às edificações vistoriadas.

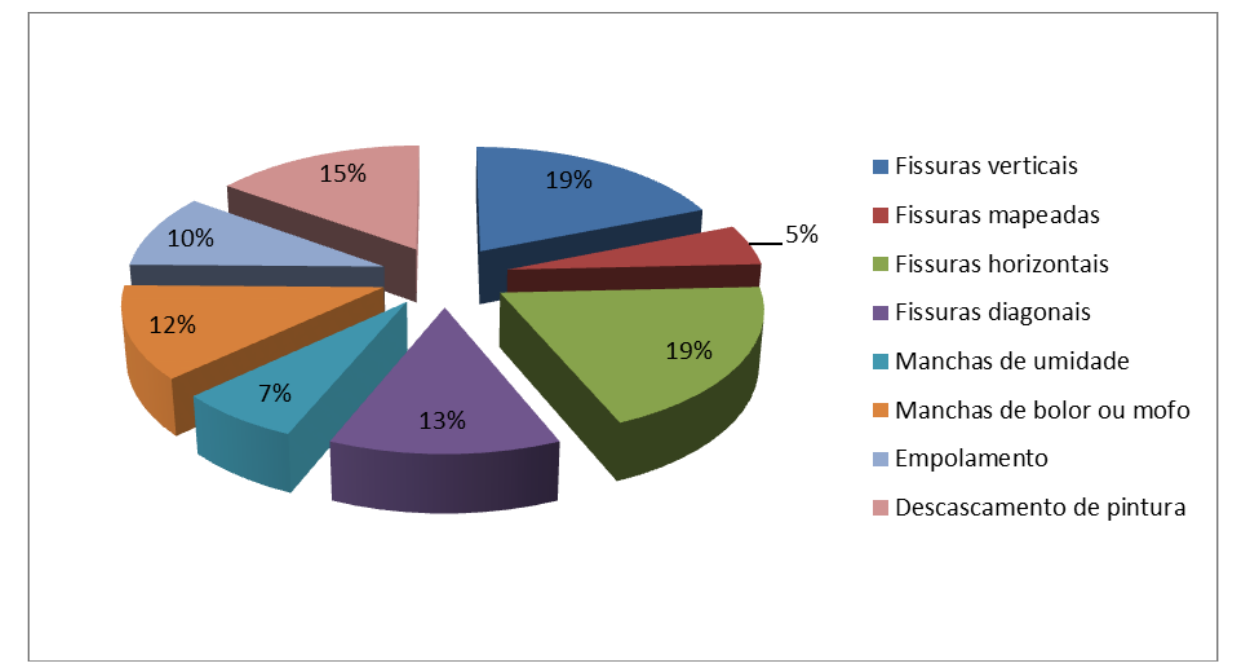

Figura 11: Frequência dos problemas patológicos identificados nas edificações vistoriadas.

No gráfico da Figura 11 foi possível identificar que as manifestações mais recorrentes foram às fissuras verticais e horizontais, representando cada uma cerca de $19 \%$ do total das manifestações identificadas, indicando problemas estruturais nas residências analisadas. Em seguida, a manifestação mais recorrente foi o descascamento de pintura, o que sugere problemas provenientes da umidade nos revestimentos das edificações.

As constatações corroboram com análise semelhante realizada por Carraro e Dias (2014) em um conjunto habitacional de interesse social na cidade de Uberlândia - MG, onde as manifestações com maior incidência nas edificações também foram às fissuras, representando aproximadamente $43 \%$ do total das manifestações patológicas identificadas e, em seguida, o descolamento de revestimentos com $22 \%$. 


\section{CONSIDERAÇÕES FINAIS}

Com a análise e o levantamento das manifestações patológicas nas 11 residências analisadas foi possível identificar que as manifestações do tipo fissuras possuíam relação com as ampliações realizadas. Por outro lado, as demais manifestações patológicas como manchas de umidade, bolor e descascamento de pintura foram mais influenciadas pela conservação dos imóveis.

Com o levantamento também da frequência de incidência das manifestações nas residências foi possível constatar um percentual incidente de 56\% de fissuras dos mais variados tipos, muitas delas relacionadas à ausência de vergas e contravergas. Os métodos de reparos indicados para os problemas apresentados basearam-se em outros estudos realizados na área e na análise visual destes problemas.

Através de informações coletadas junto aos moradores observou-se que as manifestações patológicas do tipo fissuras surgiram devido a um conjunto de fatores, em especial a ausência de elementos estruturais nas residências. Vários moradores relataram que, ao ampliarem suas casas, foram alertados por construtores da impossibilidade de algumas intervenções desejadas devido à ausência de vigas e pilares.

A maioria das manifestações encontradas durante as vistorias poderiam ser minimizadas caso na execução das casas tivessem sido tomados cuidados básicos relacionados à execução de obras. Este estudo demonstra também a importância da fiscalização na área da construção civil, tanto pelas entidades de classe como pelos órgãos públicos envolvidos em programas habitacionais.

\section{AGRADECIMENTOS}

Os autores gostariam de agradecer a todos que colaboraram para o desenvolvimento desse trabalho. Além disso, podese destacar o trabalho do Centro Universitário Assis Gurgacz, da cidade de Cascavel-PR no desenvolvimento da pesquisa.

\section{REFERÊNCIAS}

ALVES, L. G.; THOMÉ, V. M.; TOSTA, J. P. Manifestações patológicas em casas populares - uma análise de custo. Revista Estudo e Debate, v. 24, n. 2, p. 268-294, 2017.

CARRARO, C. L.; DIAS, J. F. Diretrizes para prevenção de manifestações patológicas em habitações de interesse social. Ambiente Construído, v. 14, n. 2, p. 125-139, 2014.

FREIRE, A. de A. Patologias da pintura: saiba evitá-las. Disponível em:

<https://www.aecweb.com.br/cont/m/rev/patologias-da-pintura-saiba-evitalas_6272_10_0〉. Acesso em: 10 de mai. 2019.

GIORDANI, A. Z. Levantamento e diagnóstico das manifestações patológicas em fachadas de edificações localizadas no campus da UFSC. 2016. 100 f. Trabalho de Conclusão de Curso (Graduação em Engenharia Civil) Universidade Federal de Santa Catarina, Florianópolis, SC, Brasil, 2016.

GOMES, Adriano. Patologias na construção civil - principais causas. Disponível em: < http://www.unumarquitetura.com/single-post/2016/1/11/PATOLOGIAS-NA-CONSTRU\%C3\%87\%C3\%83O-CIVIL>. Acesso em: 14 de out. 2019.

INSTITUTO BRASILEIRO DE AVALIAÇÕES E PERÍCIAS. Norma de Inspeção Predial Nacional 2012. Disponível em: http://ibape-nacional.com.br/biblioteca/wp-content/uploads/2012/12/Norma-deInspe\%C3\%A7\%C3\%A3o-Predial-IBAPE-Nacional.pdf. Acesso em: 17 de out. de 2019.

LICHTENSTEIN, Norberto Blumenfeld. Patologia das construções. Boletim Técnico. Escola Politécnica da Universidade de São Paulo, São Paulo, SP, Brasil, 1986.

MUCI, D. W. S.; NETTO, J. R. B.; SILVA, R. de A. Sistemas de recuperação de fissuras da interface alvenaria de vedação-estrutura de concreto: comparativo entre os processos executivos e análise de custo. 2014. 98 f. Trabalho 
de Conclusão de Curso (Graduação em Engenharia Civil) - Universidade Federal de Goiás, Departamento de Engenharia Civil. Goiânia, GO, Brasil, 2014.

NETTO, L. F. R.; TEIXEIRA, B. Y. Estudo das manifestações patológicas existentes na pintura e um estudo das mais decorrentes nas residências em Itaperuna/RJ. 2015. 70 f. Trabalho de Conclusão de Curso (Graduação em Engenharia Civil) - Faculdade Redentor, Itaperuna, RJ, Brasil, 2015.

PAGANIN, Ricardo. Estudo de caso: levantamento de manifestações patológicas aparentes existentes em uma universidade de Cascavel - PR. 2014. 77 f. Trabalho de Conclusão de Curso (Graduação em Engenharia Civil) Faculdade Assis Gurgacz, Departamento de Engenharia Civil. Cascavel, PR, Brasil, 2014.

REFATI, K. K. P. Inspeção em estruturas de alvenaria em blocos estruturais. 2013. 94 f. Trabalho de Conclusão de Curso (Graduação em Engenharia Civil) - Universidade Tecnológica Federal do Paraná, Departamento de Construção Civil, Pato Branco, PR, Brasil, 2013.

RICHARDSON, Roberto Jarry. et al. Pesquisa social: métodos e técnicas. 2. ed. São Paulo: EDITORA ATLAS, 1989.

RIPPLINGER, Zuleica Margô. Patologias em obras de alvenaria estrutural: soluções para evita-las. 2011.62 f. Trabalho de Conclusão de Curso (Graduação em Engenharia Civil) - Universidade de Santa Cruz do Sul, Santa Cruz do Sul, RS, Brasil, 2011.

ROSENTAL, C.; FRÉMONTIR-MUPRHY, C. Introdução aos métodos quantitativos em ciências humanas e sociais. 1. ed. Porto Alegre: INSTITUTO PIAGET, 2001.

SILVA, D. V. S. R.; SOBRINHO, C. W. P. Procedimento e tratamento para evitar fissuras nas ligações entre alvenaria e estrutura de concreto armado - Um estudo de caso. Revista de Engenharia e Pesquisa Aplicada, v. 3, n. 1, p. 91-104, 2016

SOTILLE, Mauro. Matriz GUT. Disponível em: <https://dicasgp.pmtech.com.br/matriz-gut-gravidade-urgencia-etendencia/>. Acesso em: 13 de mai. de 2019.

THOMAZ, E. Trincas em edifícios: causas, prevenção e recuperação. 1. ed. São Paulo: PINI, 1989.

VIEIRA, Matheus Assis. Patologias construtivas: conceito, origens e método de tratamento. Revista Especialize On-line IPOG, v. 1, n. 12, p. 1-15, 2016. 